\title{
Optic nerve mobilization to enhance the exposure of the pituitary stalk during craniopharyngioma resection: early experience
}

\author{
Hussam Metwali, MSc, Venelin Gerganov, MD, and Rudolf Fahlbusch, MD \\ Department of Neurosurgery, International Neuroscience Institute, Hannover, Germany
}

OBJECTIVE Preservation of the pituitary stalk and its vasculature is a key step in good postoperative endocrinological outcome in patients with craniopharyngiomas. In this article, the authors describe the surgical technique of medial optic nerve mobilization for better inspection and preservation of the pituitary stalk.

METHODS This operative technique has been applied in 3 patients. Following tumor exposure via a frontolateral approach, the pituitary stalk could be seen partially hidden under the optic nerve and the optic chiasm. The subchiasmatic and opticocarotid spaces were narrow, and tumor dissection from the pituitary stalk under direct vision was not possible. The optic canal was therefore unroofed, the falciform ligament was incised, and the lateral part of the tuberculum sellae was drilled medial to the optic nerve. The optic nerve could be mobilized medially to widen the opticocarotid triangle, which enhanced visualization of and access to the pituitary stalk.

RESULTS By using the optic nerve mobilization technique, the tumor could be removed completely, and the pituitary stalk and its vasculature were preserved in all patients. In 2 patients, vision improved after surgery, while in 1 patient it remained normal, as it was before surgery. The hormonal status remained normal after surgery in 2 patients. In the patient with preoperative hormonal deficiencies, improvement occurred early after surgery and hormonal levels were normal after 3 months. No approach-related complications occurred.

CONCLUSIONS This early experience shows that this technique is safe and could be used as a complementary step during microsurgery of craniopharyngiomas. It allows for tumor dissection from the pituitary stalk under direct vision. The pituitary stalk can thus be preserved without jeopardizing the optic nerve.

http://thejns.org/doi/abs/10.3171/2015.6.JNS141847

KEY WORDS craniopharyngioma; microsurgery; optic nerve mobilization; outcome; pituitary stalk; surgical technique

$\mathrm{C}$ RANIOPHARYNGIOMAS are tumors in the central skull base originating from the pituitary stalk. Although patients with intrasellar craniopharyngiomas usually have hormonal disturbances at the time of presentation, in patients with supradiaphragmatic craniopharyngioma, the visual symptoms dominate. , $, 2,8-8-18,20,24,32-35^{2}$

The choice of operative approach for craniopharyngioma resection depends on the surgeon's preference and experience, considering the location and configuration of the tumor. Our current concept of management of craniopharyngiomas is gross-total resection via the frontolateral approach. ${ }^{12}$ Regardless of which approach is used, the attempt to achieve radicality might increase the risk of endocrinological or visual deterioration. The major challenge that remains is the intraoperative identification and preservation of the pituitary stalk with its feeding vessels, especially in large supradiaphragmatic craniopharyngiomas. ${ }^{1,2,4,8-13,16-18,20,24,33}$
In this article, we describe a technique that enhances tumor resection while preserving the pituitary stalk. It includes unroofing of the optic canal together with incision of the falciform ligament and drilling of the lateral part of the tuberculum sellae. This additional space allows for mobilization of the optic nerve medially and dorsally. The origin of the craniopharyngioma from the pituitary stalk can be inspected, and the tumor can be separated from the stalk under vision. The early experience with the technique in 3 patients, and its advantages and potential drawbacks, are discussed.

\section{Optic Nerve Mobilization}

The growth of a craniopharyngioma has different patterns resulting in different configurations of the neurovascular structures in the suprasellar region. These different 
configurations have been described in a previous work from our institution. ${ }^{12}$

The pituitary stalk has 2 critical points during the dissection of a craniopharyngioma: the inferior end of the pituitary stalk at its entry into the sella, and the upper end of the stalk at its attachment to the floor of the third ventricle. Both points are hidden and less mobile (Fig. 1A), which renders the dissection of the tumor from the stalk at these points significantly difficult. Unroofing of the optic canal, incision of the falciform ligament, and drilling of the tuberculum sellae medial to the optic nerve allow dorsal and lateral mobilization of the optic nerve and provide a space for dissection of the tumor from the lower part of the pituitary stalk (Fig. 1B). Furthermore, this procedure allows medial mobilization of the optic nerve and widens the opticocarotid triangle. Thus, the tumor can be dissected from the upper part of the pituitary stalk under vision (Fig. 1C).

The tuberculum sellae is directly related to the sphenoidal sinus. Drilling of the tuberculum sellae medial to the optic nerve can open the sphenoidal sinus with subsequent risk of CSF leak. This area should be reconstructed with fat tissue to avoid such a complication. Due to variation of the pneumatization of the sphenoidal sinus and the size of the tuberculum sellae, careful analysis of preoperative bone window $\mathrm{CT}$ is recommended. While mobilizing the optic nerve, the course of the ophthalmic artery should be kept in mind. Special consideration should also be given to the vasculature of the optic nerve and the optic chiasm.

\section{Patient Sample}

This optic nerve mobilization technique was used recently in 3 patients with supradiaphragmatic craniopharyngioma who were operated on by the senior author (R.F.). Preoperative hormonal status was normal in 2 patients. One patient had preoperative partial pituitary in- sufficiency. One patient had a normal preoperative visual field. One patient had peripheral scotoma, and the other had partial temporal hemianopsia. After 3 months, the patients were evaluated using hormonal assay, ophthalmological assessment, and MRI.

\section{Surgical Technique \\ Skin Incision and Craniotomy}

The approach is performed with the patient's head extended and rotated slightly to the opposite side of the craniotomy. A hemicoronal skin incision is performed behind the hairline. The forehead skin is reflected inferiorly, exposing the orbital rim. The temporalis muscle is incised and then retracted downward, exposing the keyhole. A small basal frontolateral craniotomy (approximately 2.5 $\mathrm{cm}$ ) reaching laterally using the keyhole is then performed.

\section{Initial Subdural Dissection}

A semilunar inferiorly based dural incision is performed. The frontal lobe is gently retracted, exposing the arachnoid of the sylvian fissure. The arachnoid of the proximal sylvian fissure is opened and the CSF is released. Adequate CSF release is required for adequate brain relaxation.

\section{Tumor Resection}

Tumor resection is performed through the usual pathways: the subchiasmatic, opticocarotid, and carotidotemporal windows. After initial internal decompression of the tumor via the subchiasmatic window, dissection proceeds in the opticocarotid triangle. The space created in the subchiasmatic window allows the surgeon to mobilize the lateral part of the tumor medially and to find the correct subarachnoid plane of dissection. Dissection of the tumor is continued, avoiding injury to the feeding vessels
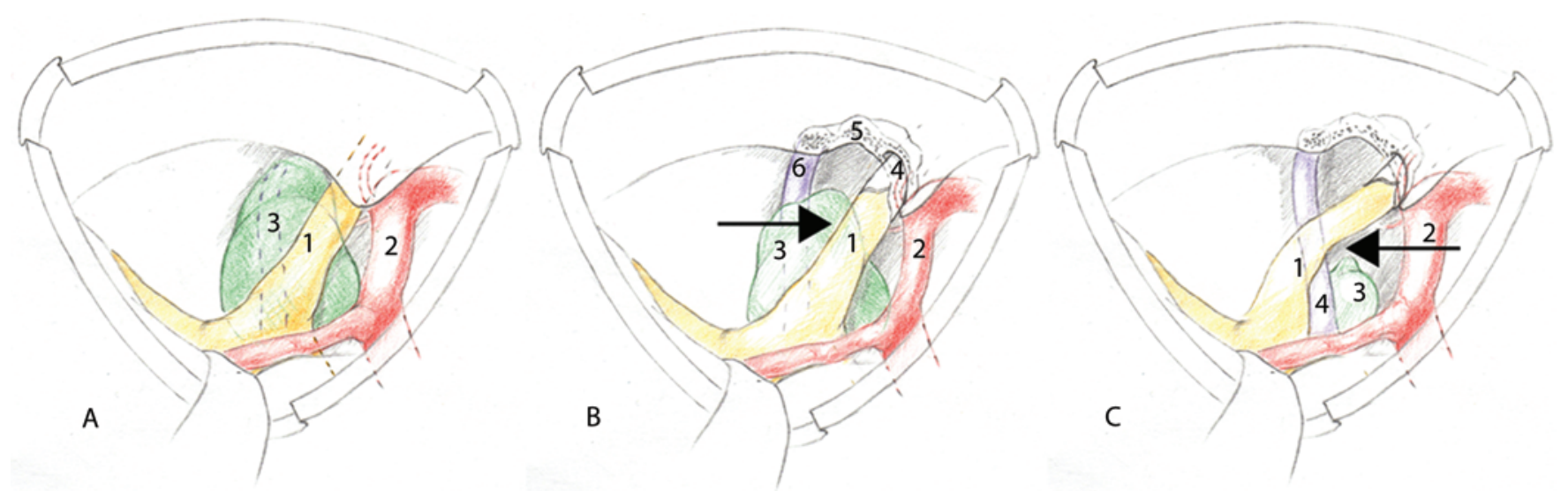

FIG. 1. Illustration showing the merits of optic nerve mobilization. A: The initial operative field view after a right frontolateral craniotomy and resection of the craniopharyngioma in the subchiasmatic space and inferior to the left optic nerve and tract. $1=$ right optic nerve, 2 = right internal carotid artery, 3 = the craniopharyngioma adherent to the pituitary stalk (dashed). B: Drilling of the tuberculum sellae, unroofing of the optic canal, and incision of the falciform ligament allow a degree of elevation and mobilization of the optic nerve laterally and provide better exposure of the tumor attached to the lower end of the stalk. The tumor can be resected under vision. $4=$ incised falciform ligament, $5=$ drilled tuberculum sellae medial to the optic nerve, $6=$ lower end of the pituitary stalk. The arrow shows the possibility of lateral and dorsal optic nerve mobilization C: Medial optic nerve mobilization to expose the tumor attached to the upper stalk. $4=$ the upper end of the pituitary stalk. The arrow shows the possibility of medial optic nerve mobilization. Copyright Lucius S. Fekonja. Published with permission. Figure is available in color online only. 
of the pituitary stalk. Bipolar coagulation should therefore be avoided whenever possible. In its area of origin, the craniopharyngioma is very adherent to the stalk. Dissection at this point should be sharp with microscissors. The pituitary stalk is partially hidden under the ipsilateral optic nerve and the optic chiasm. In some cases, the subchiasmatic space and the opticocarotid triangle are narrow, which additionally limits visualization of the pituitary stalk. Dissection of the tumor from the pituitary stalk is not possible under direct vision and can lead to excessive traction on the optic nerve. For better exposure and visualization of the pituitary stalk in these cases, we mobilize the optic nerve medially (Fig. 2A).

\section{Optic Nerve Mobilization}

The optic canal is opened superiorly and the falciform ligament incised. Then the lateral part of the tuberculum sellae is drilled (Fig. 2B). The amount of bone drilling of the tuberculum sellae medial to the optic nerve is variable, depending on the location of the pituitary stalk and the site of adherence of the tumor to the stalk. Accordingly, the surgeon can define intraoperatively how much to be drilled from the tuberculum sellae for safe medial mobilization of the optic nerve. The optic nerve is relatively freed and can be mobilized dorsally and laterally. The ex- posure of the lower end of the pituitary stalk is enhanced. The tumor attached to the lower end of the pituitary stalk can be removed under vision. Medial mobilization of the optic nerve widens the opticocarotid space and exposes the superior and inferior parts of the pituitary stalk (Fig. $2 \mathrm{C}$ and $\mathrm{D})$. This offers the possibility of safe dissection of the tumor from the pituitary stalk under direct vision (Fig. 2E).

\section{Reconstruction}

The drilled area is in direct connection to the sphenoidal air sinus. This should be covered with subcutaneous fat and tissue glue to avoid a postoperative CSF leak (Fig. $2 \mathrm{~F})$.

\section{Results}

\section{Tumor Resection}

Complete tumor resection was achieved in all cases. The resection was confirmed by operative inspection by the neurosurgeon and by analysis of postoperative images by an independent neuroradiologist and the neurosurgeon. MRI control after 3 months was performed in all cases. The follow-up confirmed the total resection, and there was no early recurrence.
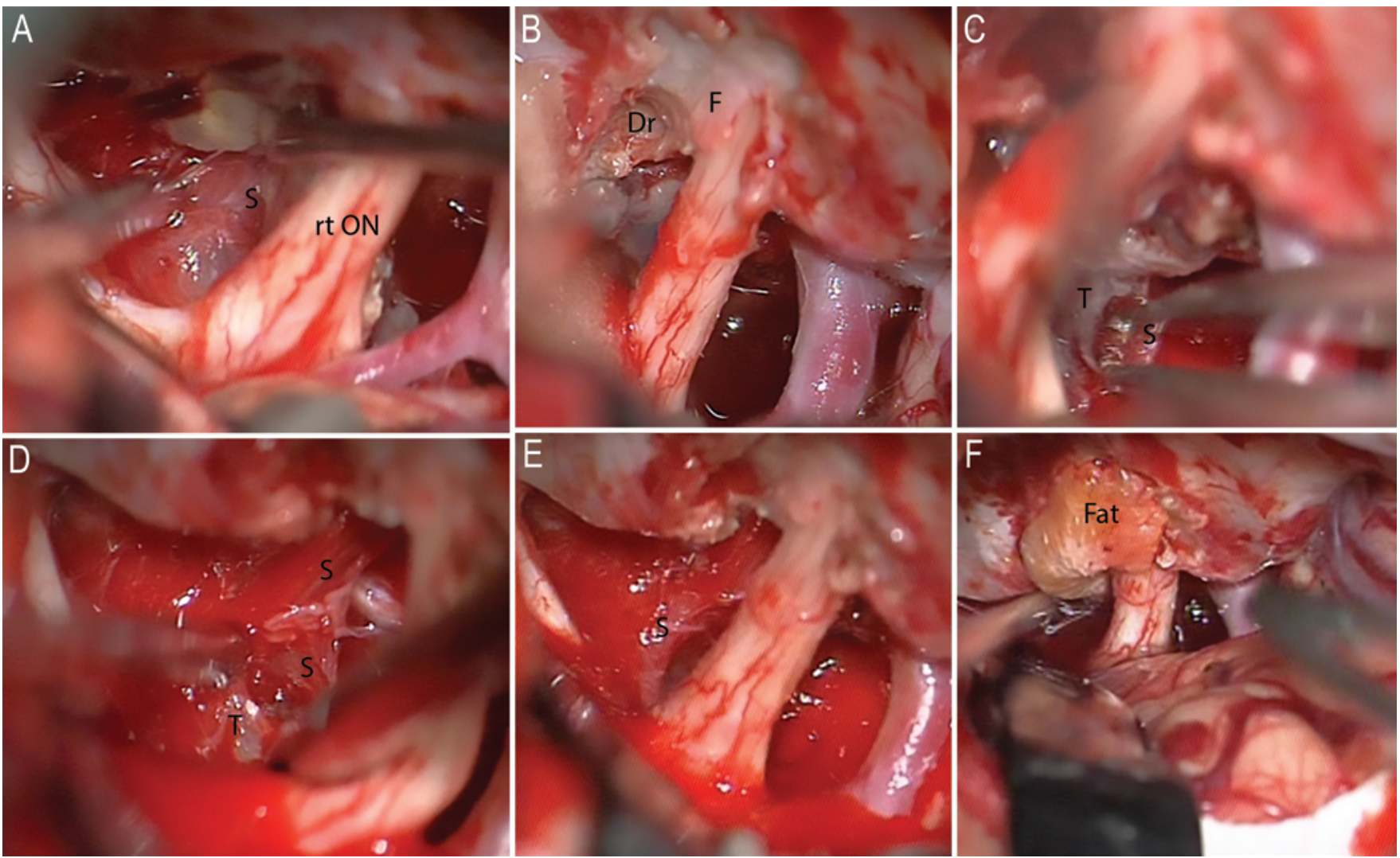

FIG. 2. Intraoperative images. A: Identification of the pituitary stalk (S). The site of attachment of the craniopharyngioma is hidden by the right optic nerve (rt ON) B: Drilling of the roof of the optic canal and the lateral part of the tuberculum sellae (Dr). The falciform ligament $(F)$ is incised. C: Medial mobilization of the optic nerve and exposure of the upper part of the pituitary stalk (S). Now the tumor (T) can be dissected under vision. D: Further dissection of the tumor medial to the optic nerve. E: Overview of the operative field showing the preserved pituitary stalk. F: Covering of the drilled area using a fat graft. Figure is available in color online only. 


\section{Endocrinological Outcome}

The pituitary stalk was anatomically and functionally preserved in all patients. Two patients had normal hormonal status after surgery. One of these patients experienced transient postoperative hyponatremia, managed with fluid restrictions. The third patient had preoperative partial pituitary insufficiency, which remained unchanged initially. Within 3 months, however, she recovered and did not need hormonal substitution. None of the 3 patients experienced postoperative diabetes insipidus.

\section{Visual Outcome}

None of the patients experienced visual deterioration. One patient had preoperative incomplete hemianopsia on the right side, which partially recovered. Another patient with preoperative scotoma showed improvement after surgery. In the third patient, the visual acuity and field of vision remained normal.

\section{Illustrative Case}

A 49-year-old woman presented with progressive visual deterioration and headache. MRI of her brain showed a suprasellar lesion elevating the floor of the third ventricle (Fig. 3A and B). The radiological appearance was consistent with a craniopharyngioma, and surgical removal via the right frontolateral approach was planned. Following the operative steps described above, the tumor was exposed and internal decompression was performed, first through the subchiasmatic space and then through the opticocarotid space. The pituitary stalk was identified posteriorly at its attachment to the floor of the third ventricle, and later the origin of the tumor from the pituitary stalk was visualized. The access to this area was limited by the right optic nerve and further dissection would require either aggressive optic nerve mobilization or blind dissection. Therefore, at this stage, the roof of the optic canal was drilled and the falciform ligament incised. The lateral part of the tuberculum sellae was also drilled toward the sphenoid sinus, but the mucosa was preserved. The increased exposure allowed resection of the tumor completely under direct visual control via the subchiasmatic and opticocarotid spaces. After tumor resection, an autologous fat graft was used to cover the drilled area. The patient was operated on while under intraoperative MRI control (Fig. 3). The tumor was completely removed (Fig. 3C and D), and the drilled area can be seen in Fig. 3D.

The patient made an uneventful recovery and had no new neurological or hormonal deficits. Postoperative visual field examination showed improvement of the preoperative visual field defect (Fig. 4).

\section{Discussion}

Craniopharyngiomas are midline tumors originating in the hypothalamic pituitary region. ${ }^{32}$ Although total resection of the tumor results in better survival benefit, craniopharyngioma surgery can be associated with a high rate of hypothalamic/hypophyseal dysfunction. The surgical procedure affects the pituitary stalk or its vasculature, resulting in postoperative endocrinological disturbance. ${ }^{11-13,15,16,18,34,35}$

The frontolateral approach is used at our institution
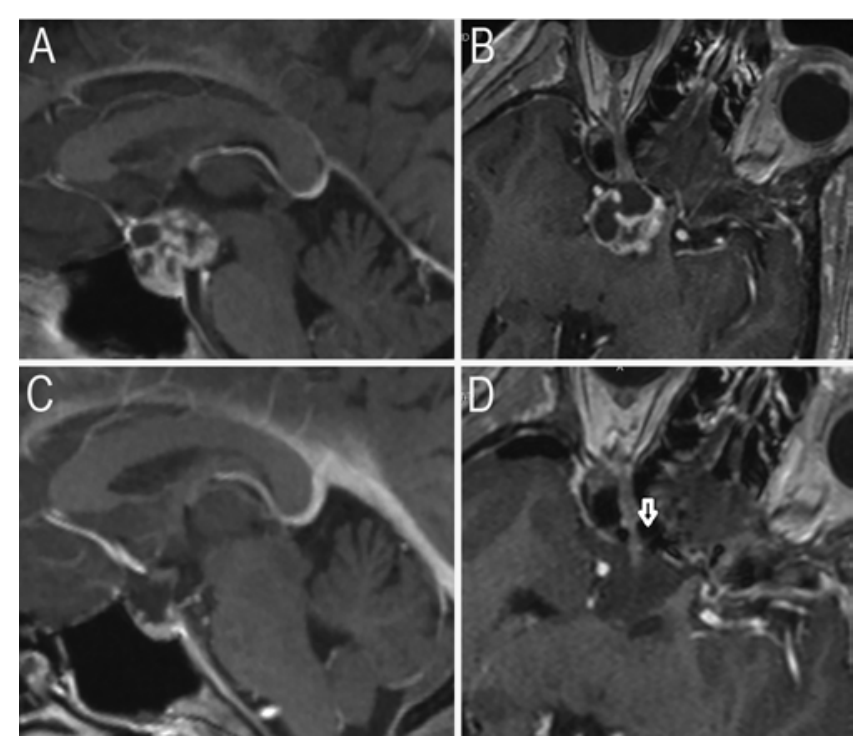

FIG. 3. Sagittal (left) and axial (right) preoperative MR images (A and $B$ ) and MR images after tumor resection ( $C$ and D). The intact pituitary stalk can be identified in $\mathbf{C}$. The drilled area medial to the optic nerve can be identified in $\mathbf{D}$ (arrow).

as the standard transcranial approach for resection of the great majority of suprasellar craniopharyngiomas. ${ }^{12}$ In this article, we present a further refinement of the technique for better preservation of the pituitary stalk and its vasculature. After the usual frontolateral approach, the optic canal is opened together with drilling of the lateral part of the tuberculum sellae. This allows medial mobilization of the optic nerve and widening of the opticocarotid triangle. The site of origin of the craniopharyngioma from the pituitary stalk comes into view. Complete separation of the tumor from the pituitary stalk without excessive traction of the optic nerve can be achieved. Furthermore, drilling of the lateral part of the tuberculum sellae along with dorsal and lateral mobilization of the optic nerve improves the exposure of the lower part of the pituitary stalk and facilitates safe resection of the inferior part of the tumor.

Operative inspection of the pituitary stalk is possible using endoscopic-assisted transcranial approaches. Endoscopic-assisted tumor resection can expose the pituitary stalk, but the surgical accessibility for resection of the adherent part of the craniopharyngioma to the stalk is limited. In some cases, the introduction of the endoscope is difficult, because of the narrow spaces between the neurovascular structures in the suprasellar space. Transsphenoidal resection of the craniopharyngioma can expose and preserve the pituitary stalk but with a higher risk of a CSF leak and a less complete resection. $5,21,23,26$

The techniques of decompression and mobilization of the optic nerve vary depending on the pathology and the aim of the surgical procedure. Unroofing of the optic canal is a well-established procedure, especially during resection of tuberculum sellae meningiomas for decompression of the optic nerve and removal of the tumor extension into the optic canal..$^{22,25}$ Anterior clinoidectomy and resection of the optic strut are also well established for resection of clinoidal meningioma or during clipping of aneurysms 


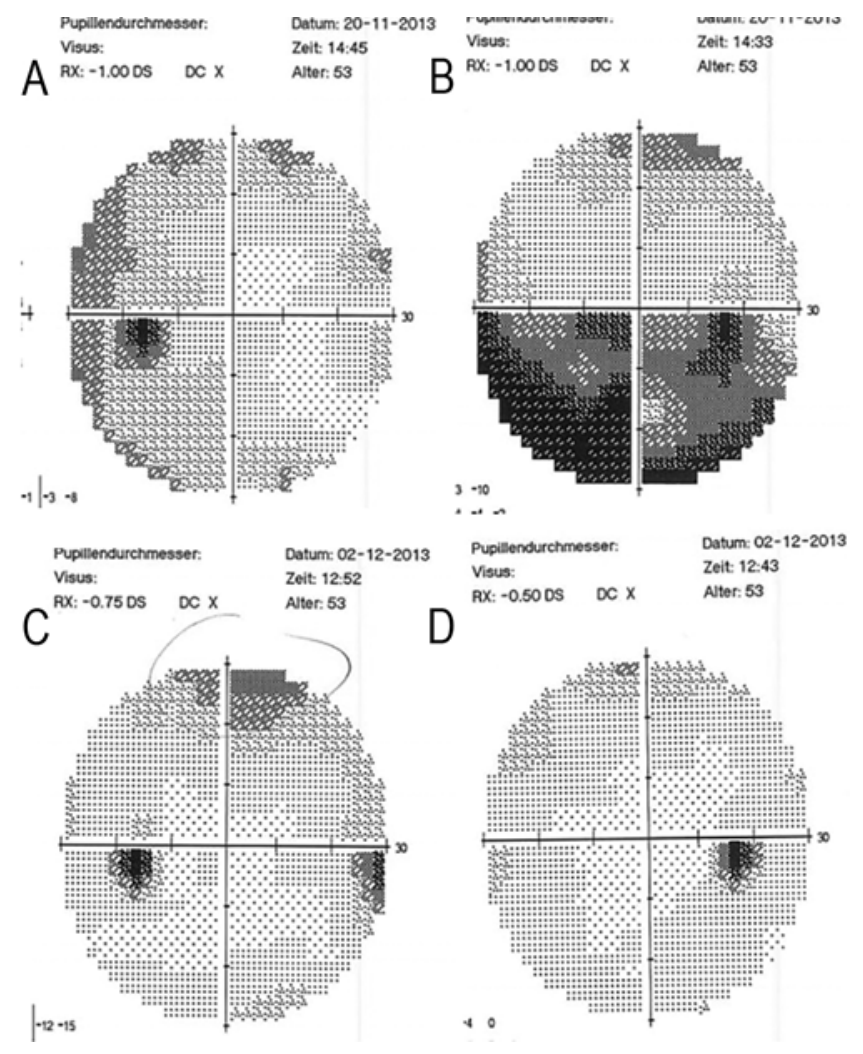

FIG. 4. The preoperative ( $A$ and $B$ ) and postoperative ( $C$ and $D)$ visual fields of the presenting case.

related to the paraclinoidal internal carotid artery. ${ }^{3,6,29-31}$ Opening of the optic canal and optic nerve decompression have also been described during transsphenoidal surgery for suprasellar lesions. ${ }^{7,19}$ Optic nerve decompression with or without mobilization can be performed without compromise of visual outcome, especially if performed by an experienced surgeon. ${ }^{27-29,31}$

For medial optic nerve mobilization, drilling of a part of the tuberculum sellae is necessary to avoid vigorous stretching of the optic nerve. The amount of drilling is variable, depending on the location of the stalk in relation to the optic nerve and optic chiasm. It is also dependent on the site of attachment of the tumor to the pituitary stalk. The surgeon should consider the course of the ophthalmic artery while mobilizing the optic nerve medially. This tailored technique is sufficient to expose the entire length of the pituitary stalk. It is also safe and not time consuming.

Covering of the drilled area of the tuberculum sellae with fat is necessary to avoid CSF leak, which can happen due to opening of the mucosa of the sphenoidal sinus. In this technique, the drilled area is relatively small and a small piece of subcutaneous scalp fat is sufficient to cover the defect. It is unnecessary to make other incisions in the abdomen or the upper thigh to gain a larger fat graft.

The potential drawback of our technique would be risk of injury to the optic nerve or to the ophthalmic artery. In our experience, although limited to only 3 patients, we never observed visual or pituitary/hypothalamic complications. There is also a potential risk of CSF leak. Cover- ing of the drilled area of the tuberculum sellae with a fat graft is mandatory to avoid CSF leak, which no patient experienced in this series.

\section{Conclusions}

The technique of medial optic nerve mobilization following optic nerve unroofing and drilling of the lateral part of the sphenoid can enhance the resection of supradiaphragmatic craniopharyngiomas. This technique provides better exposure of the pituitary stalk, allowing for safer tumor dissection from the stalk under direct vision. The pituitary stalk and its vasculature can thus be preserved. According to our early experience, the technique is safe. It can also be applied during resection of other suprasellar lesions.

\section{References}

1. Al-Mefty O, Ayoubi S, Kadri PA: The petrosal approach for the total removal of giant retrochiasmatic craniopharyngiomas in children. J Neurosurg 106 (2 Suppl):87-92, 2007

2. Aryan HE, Ozgur BM, Jandial R, Levy ML: Subfrontal transbasal approach and technique for resection of craniopharyngioma. Neurosurg Focus 18(6A):E10, 2005

3. Bassiouni H, Asgari S, Sandalcioglu IE, Seifert V, Stolke D, Marquardt G: Anterior clinoidal meningiomas: functional outcome after microsurgical resection in a consecutive series of 106 patients. Clinical article. J Neurosurg 111:10781090, 2009

4. Cabezudo Artero JM, Vaquero Crespo J, Bravo Zabalgoitia G: Status of vision following surgical treatment of craniopharyngiomas. Acta Neurochir (Wien) 73:165-177, 1984

5. Cavallo LM, Frank G, Cappabianca P, Solari D, Mazzatenta D, Villa A, et al: The endoscopic endonasal approach for the management of craniopharyngiomas: a series of 103 patients. J Neurosurg 121:100-113, 2014

6. Chang DJ: The "no-drill" technique of anterior clinoidectomy: a cranial base approach to the paraclinoid and parasellar region. Neurosurgery 64 (3 Suppl):ons96-ons106, 2009

7. Chowdhury FH, Haque MR, Goel AH, Kawsar KA: Endoscopic endonasal extended transsphenoidal removal of tuberculum sellae meningioma (TSM): an experience of six cases. Br J Neurosurg 26:692-699, 2012

8. Elliott RE, Hsieh K, Hochm T, Belitskaya-Levy I, Wisoff J, Wisoff JH: Efficacy and safety of radical resection of primary and recurrent craniopharyngiomas in 86 children. $\mathbf{J}$ Neurosurg Pediatr 5:30-48, 2010

9. Elliott RE, Wisoff JH: Surgical management of giant pediatric craniopharyngiomas. J Neurosurg Pediatr 6:403-416, 2010

10. Fahlbusch R, Hofmann BM: Surgical management of giant craniopharyngiomas. Acta Neurochir (Wien) 150:12131226, 2008

11. Fahlbusch R, Honegger J, Paulus W, Huk W, Buchfelder M: Surgical treatment of craniopharyngiomas: experience with 168 patients. J Neurosurg 90:237-250, 1999

12. Gerganov V, Metwali H, Samii A, Fahlbusch R, Samii M: Microsurgical resection of extensive craniopharyngiomas using a frontolateral approach: operative technique and outcome. J Neurosurg 120:559-570, 2014

13. Guidetti B, Fraioli B: Craniopharyngiomas. Results of surgical treatment. Acta Neurochir Suppl (Wien) 28:349-351, 1979

14. Hakuba A, Nishimura S, Inoue Y: Transpetrosal-transtentorial approach and its application in the therapy of retrochiasmatic craniopharyngiomas. Surg Neurol 24:405-415, 1985 
15. Hoffman HJ, De Silva M, Humphreys RP, Drake JM, Smith ML, Blaser SI: Aggressive surgical management of craniopharyngiomas in children. J Neurosurg 76:47-52, 1992

16. Hofmann BM, Höllig A, Strauss C, Buslei R, Buchfelder M, Fahlbusch R: Results after treatment of craniopharyngiomas: further experiences with 73 patients since 1997. J Neurosurg 116:373-384, 2012

17. Hofmann BM, Nimsky C, Fahlbusch R: Benefit of 1.5-T intraoperative MR imaging in the surgical treatment of craniopharyngiomas. Acta Neurochir (Wien) 153:1377-1390, 2011

18. Honegger J, Buchfelder M, Fahlbusch R: Surgical treatment of craniopharyngiomas: endocrinological results. J Neurosurg 90:251-257, 1999

19. Honegger J, Fahlbusch R, Buchfelder M, Huk WJ, Thierauf $P$ : The role of transsphenoidal microsurgery in the management of sellar and parasellar meningioma. Surg Neurol 39:18-24, 1993

20. Kim YH, Kim CY, Kim JW, Kim YH, Han JH, Park CK, et al: Longitudinal analysis of visual outcomes after surgical treatment of adult craniopharyngiomas. Neurosurgery 71:715-721, 2012

21. Komotar RJ, Starke RM, Raper DM, Anand VK, Schwartz TH: Endoscopic endonasal compared with microscopic transsphenoidal and open transcranial resection of craniopharyngiomas. World Neurosurg 77:329-341, 2012

22. Landeiro JA, Gonçalves MB, Guimarães RD, Klescoski J, Correa JL, Lapenta MA, et al: Tuberculum sellae meningiomas: surgical considerations. Arq Neuropsiquiatr 68:424429, 2010

23. Leng LZ, Greenfield JP, Souweidane MM, Anand VK, Schwartz TH: Endoscopic, endonasal resection of craniopharyngiomas: analysis of outcome including extent of resection, cerebrospinal fluid leak, return to preoperative productivity, and body mass index. Neurosurgery 70:110-124, 2012

24. Maira G, Anile C, Rossi GF, Colosimo C: Surgical treatment of craniopharyngiomas: an evaluation of the transsphenoidal and pterional approaches. Neurosurgery 36:715-724, 1995

25. Mariniello G, de Divitiis O, Bonavolontà G, Maiuri F: Surgical unroofing of the optic canal and visual outcome in basal meningiomas. Acta Neurochir (Wien) 155:77-84, 2013

26. Mascarenhas L, Moshel YA, Bayad F, Szentirmai O, Salek AA, Leng LZ, et al: The transplanum transtuberculum approaches for suprasellar and sellar-suprasellar lesions: avoidance of cerebrospinal fluid leak and lessons learned. World Neurosurg 82:186-195, 2014

27. Mathiesen T, Kihlström L: Visual outcome of tuberculum sellae meningiomas after extradural optic nerve decompression. Neurosurgery 59:570-576, 2006
28. Mortini P, Barzaghi LR, Serra C, Orlandi V, Bianchi S, Losa M: Visual outcome after fronto-temporo-orbito-zygomatic approach combined with early extradural and intradural optic nerve decompression in tuberculum and diaphragma sellae meningiomas. Clin Neurol Neurosurg 114:597-606, 2012

29. Sai Kiran NA, Furtado SV, Hegde AS: How I do it: anterior clinoidectomy and optic canal unroofing for microneurosurgical management of ophthalmic segment aneurysms. Acta Neurochir (Wien) 155:1025-1029, 2013

30. Seifert V, Güresir E, Vatter H: Exclusively intradural exposure and clip reconstruction in complex paraclinoid aneurysms. Acta Neurochir (Wien) 153:2103-2109, 2011

31. Spektor S, Dotan S, Mizrahi CJ: Safety of drilling for clinoidectomy and optic canal unroofing in anterior skull base surgery. Acta Neurochir (Wien) 155:1017-1024, 2013

32. Wang KC, Hong SH, Kim SK, Cho BK: Origin of craniopharyngiomas: implication on the growth pattern. Childs Nerv Syst 21:628-634, 2005

33. Yaşargil MG, Curcic M, Kis M, Siegenthaler G, Teddy PJ, Roth P: Total removal of craniopharyngiomas. Approaches and long-term results in 144 patients. J Neurosurg 73:3-11, 1990

34. Zhou ZQ, Shi XE: Changes of hypothalamus-pituitary hormones in patients after total removal of craniopharyngiomas. Chin Med J (Engl) 117:357-360, 2004

35. Zuccaro G: Radical resection of craniopharyngioma. Childs Nerv Syst 21:679-690, 2005

\section{Disclosures}

The authors report no conflict of interest concerning the materials or methods used in this study or the findings specified in this paper.

\section{Author Contributions}

Conception and design: Metwali, Fahlbusch. Acquisition of data: Metwali. Analysis and interpretation of data: Metwali, Fahlbusch. Drafting the article: Metwali, Gerganov. Critically revising the article: all authors. Reviewed submitted version of manuscript: Metwali, Fahlbusch. Approved the final version of the manuscript on behalf of all authors: Metwali. Study supervision: Gerganov, Fahlbusch. Surgeon: Fahlbusch.

\section{Correspondence}

Hussam Metwali, Rudolf-Pichlmayr-Straße 4, Hannover D-30625, Germany. email: drhussamm@yahoo.com. 